\title{
Are maladaptive brain changes the reason for burnout and medical error?
}

Rizwan A. Manji, MD, PhD, MBA, ${ }^{\mathrm{a}, \mathrm{b}}$ Jacqueline S. Manji, PhD, ${ }^{\mathrm{b}}$ and Rakesh C. Arora, MD, PhD ${ }^{\mathrm{a}, \mathrm{b}}$

Feature Editor's Introduction-The article by Manji and colleagues relates burnout to medical errors. The authors make the case that burnout, characterized by "emotional exhaustion, detachment, cynicism, and a sense of low personal accomplishment and efficacy" is pervasive in our profession, and is associated with depression and our high rates of suicide, which are twice that of the national average. If that is not bad enough, burnout appears to be associated with, if not causative of, medical errors. The personally destructive cycle of this disease in physicians perpetuates itself because harming patients by virtue of bad decision making inflicts a moral injury that contributes even further to the sense of personal burnout and depression. As pointed out by the authors, there appears to be a neuroanatomic site responsible for burnout and depression, and there is evidence-based pharmacologic therapy to address its symptoms, many of which are outlined by the American Psychiatric Association Practice Guidelines (http://psychiatryonline. org/guidelines.aspx). Manji and colleagues remind us that burnout, depression, suicidal ideation, and so on are a disease requiring treatment, not a sign of some inherent weakness in those of us who experience these symptoms. We are no more responsible for this than we would be should we develop a soft tissue infection, symptomatic coronary artery disease, or diabetes. The effectiveness of pharmacotherapy, such as a monoamine oxidase inhibitor or a selective serotonin reuptake inhibitor, substantiates the notion that burnout is a treatable illness with a physiologic/anatomic basis, and should be viewed in that light. The article successfully makes the association with medical errors undeniable. As we increasingly learn about the basis for and the benefits of treatment for mental illness, we must increase our sensitivity to its manifestation in our colleagues, and lower our threshold for its treatment. As the authors point out, we are

From the ${ }^{\text {a Department }}$ of Surgery, Max Rady College of Medicine, University of Manitoba, Winnipeg, Manitoba, Canada; and ${ }^{\mathrm{b} C}$ ardiac Sciences Program, St Boniface Hospital, Winnipeg, Manitoba, Canada.

Received for publication April 10, 2020; revisions received May 28, 2020; accepted for publication June 1, 2020; available ahead of print July 25, 2020.

Address for reprints: Rizwan A. Manji, MD, PhD, FRCSC, MBA, CR 3014-369 Tache Ave, I.H. Asper Clinical Research Institute, St Boniface Hospital, Winnipeg, Manitoba R2H 2A6 Canada (E-mail: rmanji@sbgh.mb.ca).

J Thorac Cardiovasc Surg 2021;162:1136-40

$0022-5223 / \$ 36.00$

Copyright (c) 2020 by The American Association for Thoracic Surgery

https://doi.org/10.1016/j.jtcvs.2020.06.146

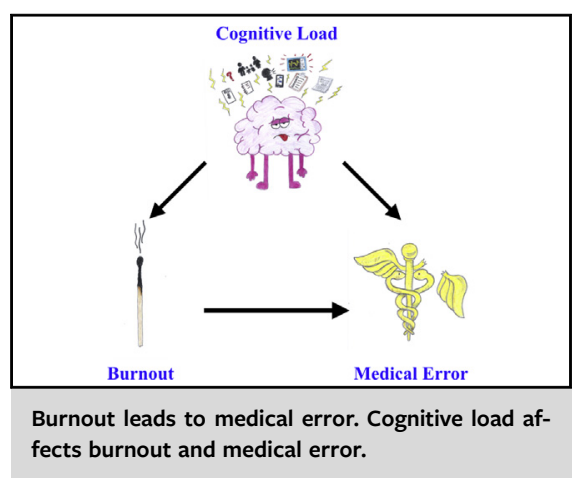

\section{CENTRAL MESSAGE \\ Burnout and medical error are problems related to cognition with biological correlates. Future effort should consider brain biology in potential solutions.}

See Commentary on page 1141.

learning that mental illness is neurobiologically based and therapy will benefit not only each of us but our patients, as well.

\section{Glenn J. R. Whitman, MD}

Burnout and medical error are recognized as substantial health care system concerns that show little evidence of improvement despite decades of attention to these problems. In this review, a description linking these 2 problems is provided. Specifically, it is proposed that burnout and medical error (diagnostic error) are related to cognitive overload (depleted working memory resources). It is also proposed that there may be biological processes occurring in similar parts of the brain that lead to both burnout and medical error. Keeping this brain biology in mind may be important in devising new solutions to the burnout and medical error problem.

\section{CLINICAL VIGNETTE}

Dr $\mathrm{X}$ has been quite distressed over the past number of months. Policies are being discussed that Dr $\mathrm{X}$ thinks will be harmful to patients and costly to the system. Dr X has 
brought up his concerns numerous times but feels ignored and powerless. He has been increasingly getting cynical about whether health care is actually about patient care. On top of that, he has already put in 120 hours in the cardiac surgery intensive care unit this week and is behind on his charts.

Dr X admits a patient postemergent coronary artery bypass graft for a non-ST-elevation myocardial infarction and heart failure needing an urgent and difficult intubation in the catheterization lab. Over the next 24 to 48 hours, the patient worsens in regard to hypoxia and hypotension. Dr X is asked to reassess the patient frequently, but he is also interrupted frequently for other issues. There are 13 other sick patients in the intensive care unit, and they all seem to need help at the same time. The electronic health record system constantly freezes, making it hard to complete the work. Dr X treats the patient with diuretics and increasing vasoactive drugs that eventually lead to renal failure and ischemic bowel needing a laparotomy.

In retrospect, $\mathrm{Dr} \mathrm{X}$ realizes that the patient likely had an aspiration pneumonia (from the urgent difficult intubation) and superimposed septic shock that should have been treated with volume and antibiotics. He does not understand why he did not think about that at the time. He is usually so on top of things. Dr X feels frustrated with the system, emotionally exhausted, cynical, and worthless. He is burned out and has harmed a patient due to his faulty thinking.

\section{BURNOUT: HURTING PHYSICIANS}

Burnout has been described as long-term, unresolvable jobrelated stress that leads to emotional exhaustion, depersonalization/feelings of detachment from one's job responsibilities, cynicism, and low personal accomplishment/efficacy (See Table 1). ${ }^{1,2}$ It asphyxiates people's ambitions, idealism, and sense of worth. ${ }^{3}$ Burnout has been reported to occur in $\sim 40 \%$ ( 2 out of every 5 ) of physicians in the United States with depression occurring in $\sim 15 \%$ to $20 \%{ }^{1}$ Rates of completed suicide-approximately $1 \%$ to $2 \%$ of physicians ${ }^{1}$ is twice the national average in some reports. ${ }^{4}$ The World Health Organization recognizes workplace burnout as an occupational phenomenon in the 11th edition of the International Classification of Diseases. ${ }^{5}$ When there is chronic imbalance between an individual and the job in 6 areas (ie, workload, control, reward, community, fairness, and values), passion erodes, and one is at risk for mental and physical health problems. ${ }^{6}$

\section{TABLE 1. Characteristics of burnout}

1. Burnout: Emotional exhaustion, depersonalization/feelings of detachment and cynicism, low personal accomplishment/efficacy

2. Forty percent of physicians have burnout; $15 \%$ to $20 \%$ have depression; and $1 \%$ to $2 \%$ complete suicide

3. Burnout is due to chronic imbalance between individual and job in terms of workload, control, reward, community, fairness, and values 4. Burnout leads to disruptive physician behavior and patient harm
Burnout is caused by a number of factors, including moral distress (not being able to do what you know to be right due to organizational/cultural obstruction), perfectionist personality, psychiatric illness, boredom, and other factors. ${ }^{2,5,6}$ In a recent survey of 15,000 physicians in more than 29 specialties, the main reason for burnout $(55 \%)$ related to overwhelming workload with factors not directly related to figuring out the patient's problem (eg, making the correct diagnosis). ${ }^{1}$ Other reasons for burnout include excessive work hours (33\%) and lack of respect from administrators, employers, colleagues, or staff $(32 \%){ }^{1}$ Studies have suggested that chronic cognitive overload and burnout are related.

\section{MEDICAL ERROR: HURTING PATIENTS}

Not only does burnout hurt physicians, but it also hurts patients (Table 2). Physician burnout affects patient care/patient safety and contributes to disruptive physician behavior. ${ }^{8}$ It is estimated that $50 \%$ of depressed physicians had some sort of patient care issues from making errors they would not normally make, expressing frustration in front of patients, being less motivated to be careful with taking patient notes, and being easily exasperated with patients. ${ }^{1}$ Despite the negative effects on physicians and patients, more than $60 \%$ of physicians did not plan to seek help for burnout and/or depression with some of the comments being that burnout was inherent in the present methods of health care delivery (system problem).

Burnout is 1 (but not the only) reason for medical error. Despite about a 40 -fold increase in the number of publications addressing the problem of patient safety/medical error from 1999 (when To Err is Human ${ }^{9}$ was published) to 2016, deaths from medical error have been reported to have increased from being the eighth leading cause of death in the United States and costing $\$ 50$ billion $^{9}$ to being the third leading cause of death ${ }^{10}$ and costing more than $\$ 100$ billion. ${ }^{11}$ Thus, the 3 big reasons people die in the United States are heart disease, cancer, and health care professionals. Health care professionals harm more patients than strokes and respiratory disease. ${ }^{10}$ Because death certificates rarely list medical error as the cause of death, it is very possible that medical errors may even be the first or second cause of death in the United States.

TABLE 2. Characteristics of medical error

1. Third leading cause of death in the United States costing more than $\$ 100$ billion

2. Most common medical error is diagnostic errors made by doctors

3. Most common diagnoses missed: infections, cardiovascular diagnoses, and cancer

4. Most common reasons for diagnostic errors: failure to order appropriate tests, failure to perform adequate history/physical exam, incorrect interpretation of diagnostic test, and failure to order appropriate consultation

5. Most common reason for diagnostic error: Cognitive biases 
The most common medical errors are diagnostic errors (ie, wrong diagnosis, delayed diagnosis, or missed diagnosis). ${ }^{10,11}$ Because diagnostic errors are generally made by doctors (leaders of the multidisciplinary team), they are the most costly and the most catastrophic of all medical errors. ${ }^{11}$ Because diagnostic error is such an enormous, costly, and underrecognized problem, organizations like the Society to Improve Diagnosis in Medicine have formed and are growing exponentially securing millions of dollars in funding. The Society to Improve Diagnosis in Medicine has been able to lobby the US government such that HR 5014 (a bill to improve the quality, appropriateness, and effectiveness of diagnosis in health care) was introduced in the House of Representatives in November 2019.

Diagnostic errors are believed to occur in anywhere from about 1 out of $5(20 \%)$ patient encounters ${ }^{11,12}$ to more than $50 \%$ of patient encounters ${ }^{13}$ depending on the complexity of the case. Diagnostic errors are more likely to occur in situations where physicians are seeing patients at the time of their initial presentation and may be under time pressure (eg, emergency departments, family medicine clinics, or internal medicine practice) versus in situations where physicians have more time and information (eg, pathology). ${ }^{14}$ The most common missed diagnoses in hospitalized patients are infections (eg, sepsis, pneumonia, and not central line infections or Clostridium difficile colitis) and cardiovascular issues (eg, acute coronary syndrome, aortic dissection, and pulmonary embolism). ${ }^{11,12}$ The most common missed diagnosis in outpatient care is cancer. ${ }^{11}$ The most common reasons for diagnostic errors are failure to order appropriate test (58\% of cases), failure to perform an adequate medical history and physical exam $(43 \%$ of cases), incorrect interpretation of diagnostic test (37\% of cases), and failure to order appropriate consultation (33\% of cases). ${ }^{15,16}$ Diagnostic errors are unintentional (errors of omission) in $75 \%$ of cases. ${ }^{17}$ The most common reason for diagnostic errors are cognitive biases (heuristics or shortcuts) and failures in thinking appropriately. ${ }^{18}$

\section{LINK BETWEEN BURNOUTAND MEDICAL ERROR}

As mentioned, the primary reason for burnout is overwhelming workload with factors not directly related to figuring out a patient's problem (making a diagnosis). ${ }^{1}$ Also as mentioned, reasons for diagnostic errors are not doing an adequate history and physical exam, not ordering appropriate tests, and incorrectly interpreting diagnostic tests. ${ }^{15,16}$ These reasons for diagnostic error may be errors related to having too much to do in too little time (overload). Hence, it appears that both burnout and diagnostic errors may be related to overload (cognitive overload), which is related to exceeding working memory capacity (limitation of the brain). Perhaps, when one is very busy, instituting shortcuts (cognitive biases) to take care of the patient problem may be the coping mechanism for the brain ${ }^{19}$ and this leads to medical error. Making errors or not performing the way one thinks he or she should may lead to the problem of moral injury, which refers to the emotional, physical, and spiritual harm people feel after "perpetrating, failing to prevent, or bearing witness to acts that transgress deeply held moral beliefs and expectations." 20 Chronic exposure to moral injury stress may then contribute to burnout. The above may be a link between burnout and diagnostic error and an important concept to keep in mind when contemplating future solutions.

\section{MEDICAL ERROR, BURNOUT, AND THE BRAIN}

Both burnout and medical error may be related to cognitive overload. Examining the literature suggests that perhaps there are brain structures that may be damaged in burnout and thus may lead to cognitive biases and diagnostic error due to some areas of overlap. To understand this better, parts of the brain involved in different types of thinking (that can lead to cognitive biases) will be explored followed by examining parts of the brain affected by burnout. Table 3 compares the brain structures involved in cognitive biases and burnout to examine the overlap.

Daniel Kahneman, a Nobel Prize Laureate, proposed a cognitive model on dual-process thinking (system 1 and system 2 thinking) that may explain the cognitive biases that lead to diagnostic errors ${ }^{21}$ (see Table 4). System 1 thinking is what humans do $\sim 95 \%$ of the time. It is automatic, impulsive, associative, emotional, very fast, and generally unconscious. System 1 thinking is influenced by environmental conditions, task characteristics, age/experience, affective state, gender, and personality. ${ }^{22}$ One can multitask with system 1 thinking consuming minimal energy. ${ }^{21}$ System 1 (automatic) thinking is an ideal system to use when one has time pressures and is overloaded but system 1 is very prone to cognitive bias errors ${ }^{21}$ and cognitive bias errors are the major reason for diagnostic error. ${ }^{18}$ Functional magnetic resonance imaging (MRI) studies localize automatic (system 1) thinking to ventromedial prefrontal cortex, basal ganglia, amygdala, lateral temporal cortex, dorsal anterior cingulate ${ }^{23}$; that is, many limbic system structures. System 2 thinking on the other hand is more deliberate, reflective, analytical, logical, and conscious. ${ }^{21}$ System 2 thinking is influenced by education, training, critical thinking skills, logical competence, rationality, feedback, and intellectual ability. ${ }^{22}$ System 2 thinking consumes a lot of energy, is slow, and one cannot multitask with system 2 thinking, which makes it a poor system to use when one is overloaded, but it is generally less prone to errors. Functional MRI studies localize controlled thinking (system 2) to lateral prefrontal cortex, medial temporal lobe, medial parietal cortex, lateral parietal cortex, rostral anterior cingulate cortex, medial prefrontal cortex, dorsomedial prefrontal cortex ${ }^{23}$; that is, many cerebral hemisphere structures.

There have been a number of biological brain studies on burnout as well. Functional MRI studies ${ }^{24}$ in participants 
TABLE 3. Brain areas involved in automatic and controlled thinking versus brain areas involved in burnout

\begin{tabular}{|c|c|c|}
\hline $\begin{array}{c}\text { Automatic: } \\
\text { System } 1\end{array}$ & Control: System 2 & Burnout \\
\hline \multirow[t]{2}{*}{$\begin{array}{l}\text { Ventromedial } \\
\text { prefrontal } \\
\text { cortex }\end{array}$} & $\begin{array}{l}\text { Dorsomedial } \\
\quad \text { prefrontal cortex } \\
\text { Lateral prefrontal cortex } \\
\text { Medial prefrontal cortex }\end{array}$ & $\begin{array}{l}\text { Right prefrontal cortex } \\
\text { (reduced thickness) } \\
\text { Medial prefrontal cortex } \\
\text { (decreased gray matter and } \\
\text { thinning) }\end{array}$ \\
\hline & $\begin{array}{l}\text { Medial parietal cortex } \\
\text { Lateral parietal cortex }\end{array}$ & $\begin{array}{l}\text { Prefrontal: Parietal functional } \\
\text { connectivity negatively } \\
\text { influenced during executive } \\
\text { cognitive performance task }\end{array}$ \\
\hline $\begin{array}{l}\text { Lateral } \\
\text { temporal } \\
\text { cortex }\end{array}$ & Medial temporal lobe & $\begin{array}{l}\text { Left superior temporal gyrus } \\
\text { (reduced thickness) } \\
\text { Anterior insular cortex } \\
\text { (reduced 5-HT1A- } \\
\text { serotonin receptor binding) } \\
\text { Hippocampus (reduced 5- } \\
\text { HT1A-serotonin receptor } \\
\text { binding) }\end{array}$ \\
\hline $\begin{array}{l}\text { Dorsal } \\
\text { anterior } \\
\text { cingulate } \\
\text { cortex }\end{array}$ & $\begin{array}{l}\text { Rostral anterior } \\
\text { cingulate cortex }\end{array}$ & $\begin{array}{l}\text { Anterior cingulate cortex } \\
\text { (decreased gray matter and } \\
\text { thinning) } \\
\text { Anterior cingulate cortex } \\
\text { (reduced 5-HT1A- } \\
\text { serotonin receptor binding) }\end{array}$ \\
\hline Amygdala & & $\begin{array}{l}\text { Amygdala and anterior } \\
\text { cingulate cortex reduced } \\
\text { functional connectivity } \\
\text { Amygdala (enlarged) }\end{array}$ \\
\hline Basal ganglia & & Caudate volume (reduced) \\
\hline
\end{tabular}

5-HT1A, 5-hydroxytryptamine 1A.

with chronic occupational stress shows reduced thickness in the right prefrontal cortex and left superior temporal gyrus, reduced caudate volume, and enlarged amygdala volumes (ie, maladaptive brain changes). Studies have also found that patients with exhaustion syndrome have reduced 5hydroxytryptamine $1 \mathrm{~A}$ receptor binding in the anterior cingulate cortex (ACC)/hippocampus/anterior insular cortex, reduced gray matter volume and thinning of cerebral cortex in the ACC and medial prefrontal cortex, increased amygdala volume, and reduced functional connectivity between the amygdala and ACC. ${ }^{24}$ Studies have also shown that high-stress situations negatively influence prefrontal cortex function and prefrontal-parietal functional connectivity during an executive cognitive performance task. ${ }^{24}$ The prefrontal cortex is important for inhibiting cognitive biases and for undergoing system 2 thinking ${ }^{25}$ as well as being important for memory and attention. ${ }^{26}$

Table 3 lists the parts of the brain involved/affected in automatic thinking, controlled thinking, and burnout. It is interesting that parts of the brain influenced by burnout have some degree of overlap with parts of the brain involved
TABLE 4. Comparison of the 2 systems of thinking

\begin{tabular}{lll}
\hline \multicolumn{1}{c}{ Variable } & \multicolumn{1}{c}{ System $\mathbf{1}$} & \multicolumn{1}{c}{ System $\mathbf{2}$} \\
\hline Frequency of use & $95 \%$ & $5 \%$ \\
Characteristics & Automatic & Deliberate \\
& Impulsive & Reflective \\
& Associative & Logical \\
& Emotional & Analytical \\
& Fast & Slow \\
& Generally unconscious & Conscious \\
& Ability to multitask & Unable to multitask \\
& Environmental conditions & Education/intellectual \\
& Task characteristics & ability \\
& Age/experience & Training \\
& Affective state & Critical thinking skills \\
& Gender & Logical competence \\
& Personality & Rationality \\
& & Feedback \\
Energy & Minimal & High \\
expenditure & & \\
\hline Risk of error & High & Low \\
\hline
\end{tabular}

in automatic and controlled thinking, leading to the following hypothesis: Perhaps burnout changes the brain, making it harder to do controlled thinking. It appears that burnout leads to thinning or reduced connectivity type changes in parts of the brain important for controlled thinking and expansion or changed connectivity in parts of the brain important for automatic thinking. Perhaps maladaptive brain changes from burnout lead to less system 2 thinking and thus more automatic system 1 thinking occurs that is more prone to errors.

\section{POSSIBLE SOLUTIONS AND FUTURE DIRECTIONS}

It is very interesting that within 200 years, we have been able to explore space and genetically modify organisms, but we have not been able to fix the problem of medical error. A detailed discussion of possible solutions will be the topic of a future review, but it is important that these problems get solved.

Solutions that are being explored are education/awareness, decreasing cognitive load by using technology such as artificial intelligence, using techniques such as mindfulness training and cognitive behavioral therapy, and perhaps even thinking of drug therapy to change the brain. ${ }^{2,24}$ Because medical error is the third leading cause of death after heart disease and cancer, there clearly is a need for more research funding to explore ways to decrease diagnostic errors.

If one entertains the hypothesis that there are biological brain processes that lead to both diagnostic errors and burnout, when devising solutions one should consider addressing the biology of the brain. By way of analogy, once the pathophysiology of pressure and volume overload resulting in damage to myocardium was understood, therapies were developed (eg, antihypertension drugs and 
diuretics) to mitigate ongoing injury. Studies are currently being done to understand cognitive overload better. ${ }^{27}$ If one accepts the premise that cognitive overload contributes to both burnout and diagnostic error as well as understand that there are physical limits on what the brain can do, then measures have to be put in place (by health care institutions) to not place physicians into situations where the limits of brain biology will lead to failure. It is also important to formally educate trainees and practicing physicians about cognitive psychology and to teach them to recognize signs of overload and methods to cope such as asking for help. Because burnout and medical error may be due to biological brain processes similar to heart failure being related to biological heart processes, there should be no shame or feelings of weakness in asking for help. Realizing that $\sim 95 \%$ of what we do is system 1 related (ie, automatic), health care institutions need to create environments where it is difficult (based on infrastructure and processes of care) to act in a way that will lead to medical error.

\section{CONCLUSIONS}

Burnout and medical error are significant problems that are at least partly related to cognitive overload or maladaptive brain changes, and considering these brain changes may offer innovative solutions in the future. Resources on burnout can be obtained from the Society of Thoracic Surgeons website (https://www.sts.org/publications/videos/ strategies-surgeons-prevent-burnout). Resources on medical errors can be obtained from the Society to Improve Diagnosis in Medicine website (https://www.improvediagnosis.org).

\section{Conflict of Interest Statement}

Dr Arora has received an unrestricted educational grant from Pfizer Canada Inc and honoraria from Mallinckrodt Pharmaceuticals, Abbott Nutrition, and Edwards Lifesciences for work unrelated to this work. All other authors reported no conflicts of interest.

The Journal policy requires editors and reviewers to disclose conflicts of interest and to decline handling or reviewing manuscripts for which they may have a conflict of interest. The editors and reviewers of this article have no conflicts of interest.

\section{References}

1. Kane L. Medscape national physician burnout \& suicide report 2020: the generational divide. Available at: https://www.medscape.com/slideshow/2020-lifestyleburnout-6012460. Accessed July 31, 2020.

2. West C, Dyrbye L, Erwin P, Shanafelt T. Interventions to prevent and reduce physician burnout: a systematic review and meta-analysis. Lancet. 2016;388: 2272-81.

3. Michel A. Burnout and the brain. Available at: https://www.psychological science.org/observer/burnout-and-the-brain. Accessed July 31, 2020.

4. Anderson P. Doctors' suicide rate highest of any profession. Available at: https:// www.webmd.com/mental-health/news/20180508/doctors-suicide-rate-highestof-any-profession\#1. Accessed July 31, 2020.
5. World Health Organization. Burn-out an "occupational phenomenon": International Classification of Diseases. Available at: https://www.who.int/mental_ health/evidence/burn-out/en/. Accessed July 31, 2020.

6. Leka S, Jain A, World Health Organization. Health impact of psychosocial hazards at work: an overview. Available at: https://apps.who.int/iris/handle/10665/ 44428. Accessed July 31, 2020.

7. Iskander M. Burnout, cognitive overload, and metacognition in medicine. Med Sci Educ. 2019;29:325-8.

8. Panagioti M, Geraghty K, Johnson J, Zhou A, Panagopoulou E, Chew-Graham C, et al. Association between burnout, safety, professionalism, and patient satisfaction: a systematic review and meta-analysis. JAMA Intern Med. 2018;178: 1317-30.

9. Institute of Medicine Committee on Quality of Health Care in America. In: Kohn L, Corrigan JM, Donaldson M, eds. To Err Is Human: Building a Safer Health Care System. Washington DC: National Academy Press; 2000 .

10. Makary M, Daniel M. Medical error-the third leading cause of death in the US. BMJ. 2016;353:i2139.

11. Newman-Toker DE, Schaffer AC, Yu-Moe CW, Nassery N, Saber Tehrani AS, Clemens GD, et al. Serious misdiagnoses-related harms in malpractice claims: the "big-three"- vascular events, infections, and cancers. Diagnosis (Berl). 2019;6:227-40.

12. Tudela P, Carreras A, Ballester M. Diagnostic errors in emergency departments. Med Clin. 2017; 149:170-5.

13. Meyer A, Payne V, Meeks D, Rao R, Singh H. Physicians' diagnostic accuracy, confidence, and resource requests: a vignette study. JAMA Intern Med. 2013;173: 1952-8.

14. Singh H, Mayer A, Thomas E. The frequency of diagnostic errors in outpatient care: estimations from three large observational studies involving US adult populations. BMJ Qual Saf. 2014;23:727-31.

15. Kachalia M, Gandhi T, Puopolo A, Yoon C, Thomas E, Griffey R, et al. Missed and delayed diagnoses in the emergency department: a study of closed malpractice claims from 4 liability insurers. Ann Emerg Med. 2007;49: 196-205.

16. Singh H, Giardina TD, Meyer A, Forjuoh S, Reis M, Thomas E. Types and origins of diagnostic errors in primary care settings. JAMA Intern Med. 2013;173: 418-25.

17. Leape L, Brennan T, Laird N, Lawthers A, Local A, Barnes B, et al. The nature of adverse events in hospitalized patients. Results of the Harvard medical practice study II. N Engl J Med. 1991;324:377-84.

18. O'Sullivan ED, Schofield SJ. Cognitive bias in clinical medicine. J R Coll Physicians Edinb. 2018;48:225-32.

19. Croskerry P. ED cognition: any decision by anyone at any time. CJEM. 2014;16: 13-9.

20. Bailey M. Too many tests, too little time: doctors say they face 'moral injury' because of a business model that interferes with patient care. Available at: https://www.washingtonpost.com/health/too-many-tests-too-little-time-doctorssay-they-face-moral-injury-because-of-a-business-model-that-interferes-withpatient-care/2020/01/31/c00e9d58-3d3a-11ea-8872-5df698785a4e_story.html. Accessed July 31, 2020.

21. Kahneman D. Thinking Fast and Slow. 1st ed. New York: Farrar, Straus, and Giroux; 2011

22. Saposnik G, Redelmeier D, Ruff C, Tobler P. Cognitive biases associated with medical decisions: a systematic review. BMC Med Inform Decis Mak. 2016;16: 138.

23. Lieberman MD. Social cognitive neuroscience: a review of core processes. Annu Rev Psyschol. 2007;58:259-89.

24. Savic I, Perski A, Osika W. MRI shows that exhaustion syndrome due to chronic occupational stress in associated with partially reversible cerebral changes. Cereb Cortex. 2018;28:894-906.

25. Goel V, Dolan RJ. Explaining modulation of reasoning by belief. Cognition. 2003;87:B11-22.

26. Savic I. Structural changes of the brain in relation to occupational stress. Cereb Cortex. 2015;25:1554-64.

27. Dias R, Ngo-Howard M, Boskovski M, Zenati M, Yule S. Systematic review of measurement tools to assess surgeons' intraoperative cognitive workload. $\mathrm{Br} J$ Surg. 2018;105:491-501.

Key Words: medical error, burnout, cognitive overload, fMRI, brain biology 